\title{
The behavioral and immunological impact of maternal separation: a matter of timing
}

\author{
Susana Roque ${ }^{1,2 \dagger}$, Ana Raquel Mesquita ${ }^{1,3 \dagger}$, Joana A. Palha ${ }^{1,2}$, Nuno Sousa ${ }^{1,2}$ and \\ Margarida Correia-Neves ${ }^{1,2} *$
}

\author{
${ }^{1}$ Life and Health Sciences Research Institute, School of Health Sciences, University of Minho, Braga, Portugal \\ 2 ICVS/3B's - PT Government Associate Laboratory, Braga, Portugal \\ ${ }^{3}$ Neuropsychophysiology Laboratory, Center for Research in Psychology (CIPsi), School of Psychology, University of Minho, Braga, Portugal
}

\section{Edited by:}

James P. Herman, University of

Cincinnati, USA

\section{Reviewed by:}

Francesca R. D'Amato, National

Research Council, Italy

Terrence Deak, Binghamton

University, USA

\section{*Correspondence:}

Margarida Correia-Neves, Life and Health Sciences Research Institute,

School of Health Sciences, University of Minho, Campus de Gualtar.

4710-057 Braga, Portugal

e-mail: mcorreianeves@ecsaude.

uminho.pt

${ }^{+}$Susana Roque and Ana Raquel Mesquita have contributed equally to this work.
Maternal separation (MS), an early life stressful event, has been demonstrated to trigger neuropsychiatric disorders later in life, in particular depression. Experiments using rodents subjected to MS protocols have been very informative for the establishment of this association. However, the mechanism by which MS leads to neuropsychiatric disorders is far from being understood. This is probably associated with the multifactorial nature of depression but also with the fact that different research MS protocols have been used (that vary on temporal windows and time of exposure to MS). In the present study, MS was induced in rats in two developmental periods: for $6 \mathrm{~h}$ per day for 14 days between postnatal days 2-15 $\left(\mathrm{MS}_{2-15}\right)$ and 7-20 ( $\left.\mathrm{MS}_{7-20}\right)$. These two periods were defined to differ essentially on the almost complete $\left(\mathrm{MS}_{2-15}\right)$ or partial $\left(\mathrm{MS}_{7-20}\right)$ overlap with the stress hypo-responsive period. Behavioral, immunological, and endocrine parameters, frequently associated with depressive-like behavior, were analyzed in adulthood. Irrespectively from the temporal window, both MS exposure periods led to increased sera corticosterone levels. However, only $\mathrm{MS}_{2-15}$ animals displayed depressive and anxious-like behaviors. Moreover, $\mathrm{MS}_{2-15}$ was also the only group presenting alterations in the immune system, displaying decreased percentage of $\mathrm{CD}^{+} \mathrm{T}$ cells, increased spleen T cell CD4/CD8 ratio, and thymocytes with increased resistance to dexamethasone-induced cell death. A linear regression model performed to predict depressive-like behavior showed that both corticosterone levels and T cell CD4/CD8 ratio explained $37 \%$ of the variance observed in depressive-like behavior. Overall, these findings highlight the existence of "critical periods" for early life stressful events to exert programing effects on both central and peripheral systems, which are of relevance for distinct patterns of susceptibility to emotional disorders later in life.

Keywords: maternal separation, depressive-like behavior, $\mathrm{CD8}^{+} \mathrm{T}$ cells, $\mathrm{T}$ cell $\mathrm{CD} 4 / \mathrm{CD} 8$ ratio, corticosterone, anxious-like behavior

\section{INTRODUCTION}

Depression is a devastating and prevalent mental disorder that causes great disability in modern societies and is predicted to rank in the second position for premature death in 2030 (Mathers and Loncar, 2006). The inability to adequately cope with stress has been implicated as an important factor on the onset and exacerbation of depression (Dinan, 2005; Cohen et al., 2007). Stressful events during the first days of life have been shown to impact on adult behavior (Aisa et al., 2007; Garner et al., 2007; Lee et al., 2007; Seckl, 2008; Mesquita et al., 2009) and to increase vulnerability to neuropsychiatric diseases (Nemeroff, 2004).

The impact of early developmental stressors on neuroendocrine homeostasis, particularly on the hypothalamic-pituitary-adrenal (HPA) axis, is well-recognized (Meaney et al., 1989; Liu et al., 1997; Lehmann et al., 2002). Maternal separation (MS), one of the best well-studied developmental disruptors, is documented to interfere with the maturation process of the HPA axis (Clarke, 1993; Plotsky and Meaney, 1993; Slotten et al., 2006) as well as with other physiological systems such as serotoninergic neurotransmission (Mesquita et al., 2007).

Particular relevant for MS-induced depressive-like behavior are studies using the forced swimming test (FST), revealing increased immobility time in animals submitted to MS (3-4 h per day during the first 15 postnatal days, which overlaps most of the stress hypo-responsive period in rodents) when compared with animals reared in typical housing conditions (Ruedi-Bettschen et al., 2005; Lee et al., 2007; Lambas-Senas et al., 2009; Martisova et al., 2012). Similarly, with respect to the anhedonic dimension of depression, measured by the sucrose preference test (SPT), MS animals display decreased sucrose consumption (Michaels and Holtzman, 2007). However, these results have not been confirmed by others, with respect to both immobility time in the FST (Marais et al., 2008) and sucrose consumption in the SPT (Shalev and Kafkafi, 2002). These discrepancies in the literature, although possibly caused by small changes in the MS protocols used (Schmidt et al., 2011), deserve further investigation, specifically on the mechanisms underlying depressive-like behavior. 
Alterations in the immune system have been associated with both early stressful life events and depressive-like behavior (Miller, 2010). However, surprisingly, the potential interplay of the immune system and depression has only been scarcely explored in the MS model. So far, studies in non-human primates early deprived from social contact showed that there is a decrease in the ratio of the two most important $\mathrm{T}$ lymphocyte populations, the $\mathrm{CD}^{+}$and the $\mathrm{CD} 8^{+}$T cells (CD4/CD8), and a significant increase in the number and activity of natural killer (NK) cells (Lewis et al., 2000). Similarly, a decrease in the percentage of CD4 ${ }^{+} \mathrm{T}$ cells and an increase in $\mathrm{CD}^{+} \mathrm{T}$ cells were detected in children deprived of maternal care (Gogberashvili, 2006). However, no effect on cell number was observed in rodents submitted to MS (Kruschinski et al., 2008). Considering that the function of the immune cells can be inferred by parameters such as the type and quantity of cytokines produced, it is of notice the short- (Dimatelis et al., 2012) and long-term (Avitsur et al., 2013) decrease in cytokines and chemokines production observed in animals submitted to MS.

To further understand the interplay between the HPA axis and several parameters of the immune system and their relationship with depressive-like behavior, we made use of MS protocols. The duration of the MS period used in this study ( $6 \mathrm{~h} /$ day), previously used by our team and others (Matthews and Robbins, 2003; Colorado et al., 2006; Mesquita et al., 2007), was selected to induce a significant disruption in the mother-pup interaction. Moreover, to identify critical developmental periods relevant for the emergence of these phenotypes, we applied the MS protocol in two neurodevelopmental time windows. One that overlaps most of the stress hypo-responsive period in rats [that usually occurs between postnatal day 4-14 (Schmidt et al., 2011)], and another in which the MS starts after the first postnatal week, where some maturation of the HPA axis has already occurred.

\section{MATERIALS AND METHODS ANIMALS AND MATERNAL SEPARATION PROTOCOL}

The results presented in the study are originated from two independent experiments. Wistar rats (Charles River, Barcelona, Spain) were used in the experiments and maintained under standard laboratory conditions with artificial $12 \mathrm{~h}$ light/dark cycle: lights on from 8:00 a.m. to 8:00 p.m., ambient temperature of $22^{\circ} \mathrm{C}$, and $55 \%$ of relative humidity; food and water were available ad libitum. The mating procedure was the same for all females. A male was introduced in the female's cage where two virgin females were housed, at the beginning of the dark cycle. Vaginal plug was examined at the beginning of the light cycle. When the presence of the vaginal plug was observed the female was individually housed until delivery. In each experiment, 9-12 females primiparous rats were used. Nest material was provided to each dam and no bedding changes were performed in the last days of pregnancy. The day on which a female rat showed a vaginal plug was designated as embryonic day 0 and the day of delivery as postnatal day 0 . Litters were delivered by spontaneous partum on gestation day 22. Pups from all litters were mixed on the day of delivery, and randomly assigned to each dam; the size of each litter was adjusted to $8(n=4$ male and $n=4$ female, whenever possible). Each dam and the corresponding litter were randomly assigned to one of the following experimental groups (three to five litters for each group): (a) MS from the $2^{\text {nd }}$ to the $15^{\text {th }}$ postnatal day $\left(\mathrm{MS}_{2-15}\right) ;(\mathrm{b}) \mathrm{MS}$ from the $7^{\text {th }}$ to the $20^{\text {th }}$ postnatal day $\left(\mathrm{MS}_{7-20}\right)$; and (c) control group with no MS (Cont).

In each experiment, pups from the MS groups were daily separated from their mothers between 9 a.m. and 3 p.m. as previously described (Mesquita et al., 2007); each litter was placed together in a new cage, inside an incubator at $33-35^{\circ} \mathrm{C}$ in order to maintain constantly the body temperature of the pups, as previously described (Diehl et al., 2012; Cao et al., 2013). After the $6 \mathrm{~h}$ of separation, each MS litter returned to their home cages, where the dam remained. Pups from control litters were left undisturbed with their dams until the weaning day (P21). In the present study, only males, pair-housed at weaning, were analyzed. All experiments were conducted in accordance with National and European regulations (European Union Directive 86/609/EEC) and were approved by the National Veterinary Directorate and by the local Animal Ethical Committee.

\section{BEHAVIORAL TESTS}

At 3 months of age, behavior was evaluated in the open-field (OF) followed by the FST with a 1-day interval. The animals performed both behavioral tests.

In the OF, the animals were individually tested during $5 \mathrm{~min}$ in an arena formed by a white square base $(43.2 \mathrm{~cm} \times 43.2 \mathrm{~cm})$ surrounded with acrylic transparent walls (ENV - 515; MedAssociates, VT, USA). Illumination was provided by a white bright light. The session started with the animal placed in the center of the arena and, using a system of 16 evenly spaced infra-red sourced and sensors juxtaposed around the periphery of the four sides of the chamber (at $2.5 \mathrm{~cm}$ height) with the help of the tracking software that detects solely the movement of the center of the animal's body (SOF-811, Med Associates, VT, USA). These sensors were connected to a computer, which allowed the following parameters to be recorded: (a) time spent in the central area of the arena $(10.8 \mathrm{~cm} \times 10.8 \mathrm{~cm}$; a measure of anxious-like behavior); (b) total distance traveled (a measure of general locomotor activity); and (c) number and duration of rears, manually recorded by two experimenters independently (a measure of exploratory activity).

The FST was chosen to assess behavioral despair, a measure of depressive-like behavior. For this test animals were placed in transparent acrylic cylinders with $40 \mathrm{~cm}$ of diameter filled with water $\left(25^{\circ} \mathrm{C}\right)$ to a depth $(50 \mathrm{~cm}$ depth $)$ such that the animals had no solid support for their rear paws. The test lasted for $5 \mathrm{~min}$ and was preceded, $24 \mathrm{~h}$ before, by a $10 \mathrm{~min}$ pre-test session. At the end of each session, animals were dried and placed under a heating lamp for 15 min before returning to their home cages. The cylinders were filled with fresh water after each trial. A video camera was used to record test sessions from a top angle; video recordings were later scored by an investigator blind to the experimental details. Time of immobility and latency to immobility were computed.

\section{CORTICOSTERONE DETERMINATION}

Blood samples were collected at sacrifice between 10 and 12 a.m.; the interval between transferring animals from their undisturbed environment to decapitation was kept under 60 s. Serum corticosterone levels were assessed by radioimmunoassay, using 
ImmuChemTM Corticosterone-125I kits (MP Biomedicals, LLC, Orangeburg, NY, USA). The detection limit of the assay was $7.7 \mathrm{ng} / \mathrm{mL}$.

\section{IMMUNE CELLS PHENOTYPING Flow cytometry}

To evaluate the phenotype of distinct immune system populations by flow cytometry, single-cell suspensions from spleen and thymus were prepared. Splenic erythrocytes were depleted by incubation with a hemolytic solution $\left(155 \mathrm{mM} \mathrm{NH}_{4} \mathrm{Cl}, 10 \mathrm{mM} \mathrm{KHCO}_{3}, \mathrm{pH}\right.$ 7.2) for $5 \mathrm{~min}$ at room temperature. For cell surface staining, $5 \times 10^{5}$ cells were used from each individual rat and incubated with specific antibodies, according to Table 1, for $20 \mathrm{~min}$ on ice. Cell surface markers were analyzed using specific antibodies for CD11 b/c (OX-42), CD45RA (OX-33) (Caltag, CA, USA), CD161 (10/78), CD4 (W3/25), CD8 (G28) (BioLegend, San Diego, CA, USA), and CD3 (G4.18) (eBiosciences, San Diego, CA, USA). Cells were fixed with $2 \%$ formaldehyde after staining. Fifty thousand events were acquired on a FACSCalibur flow cytometer (Becton Dickinson, NJ, USA) using the Cell Quest software (Becton Dickinson, NJ, USA); analyses of the cell populations were performed using FlowJo software (Tree Star, Ashland, OR, USA).

\section{IN VITRO THYMOCYTE TREATMENT WITH DEXAMETHASONE}

Thymocytes were resuspended in DMEM (supplemented with $10 \%$ heat inactivated FCS, $10 \mathrm{mM}$ HEPES buffer, $1 \mathrm{mM}$ sodium pyruvate, $2 \mathrm{mM}$ L-glutamine, $50 \mu \mathrm{g} / \mathrm{mL}$ streptomycin, and $50 \mathrm{U} / \mathrm{mL}$ penicillin, all from Invitrogen, CA, USA), plated into 96-well plates $\left(1.5 \times 10^{6}\right.$ cells $\left./ \mathrm{mL}\right)$, and treated, with or without $10 \mu \mathrm{M}$ of dexamethasone (Sigma, St Louis, USA), for $4 \mathrm{~h}$. To analyze cell death, cells were stained for CD4 (W3/25), CD8 (G28), annexin $\mathrm{V}$, and 7AAD (BioLegend, San Diego, CA, USA), in accordance with Table 2 and the manufacture instructions. Cells were analyzed by flow cytometry as already described.

\section{STATISTICAL ANALYSIS}

To calculate the number of animals used in the experiments, we performed a power analysis (using $\mathrm{G}^{\star}$ Power 3.1.7). To compare the three independent groups, an one-way ANOVA test should be used and, assuming a large effect size $(f=0.4)$, an alpha of 0.05 , and a statistical power of $0.5,36$ animals (12/group) were needed. In order to confirm our results, we performed two independent experiments. All dependent variables were assessed for normality. One-way ANOVA, followed by post hoc Bonferroni tests (when main effects were observed significant), was performed in order to assess group differences. To estimate the effect size, we calculated the $\eta^{2}$ (dividing the between-groups sum of squares by the total sum of squares); $\eta^{2} \geq 0.01$ indicates a small, $\geq 0.06$ medium, and $\geq 0.14$ large effects (Cohen, 1988).

A linear regression was conducted in order to predict immobility in the FST, using corticosterone levels and T cell CD4/CD8 ratio as potential predictors. Significance is referred as ${ }^{\star} p<0.05$.

\section{RESULTS}

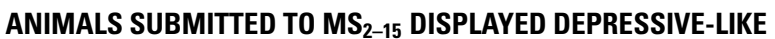
BEHAVIOR

In the FST, only the animals from the group separated earlier $\left(\mathrm{MS}_{2-15}\right)$ displayed shorter latency time to immobility (Figure 1A;
Table 1 | Antibodies used for the identification of different immune cells.

\begin{tabular}{|c|c|c|}
\hline Immune cells & Phenotype spleen cells & \\
\hline $\mathrm{CD} 4+\mathrm{T}$ cells & $\begin{array}{l}\mathrm{CD}^{+} \mathrm{CD}^{+} \text {(gated lymphocytes in FSC, } \\
\mathrm{SSC} \text { ) }\end{array}$ & \\
\hline $\mathrm{CD}^{+} \mathrm{T}$ cells & $\begin{array}{l}\mathrm{CD}^{+} \mathrm{CD}^{+} \text {(gated lymphocytes in FSC, } \\
\mathrm{SSC} \text { ) }\end{array}$ & \\
\hline B cells & $\begin{array}{l}\text { CD45Ra+ (gated lymphocytes in FSC, } \\
\mathrm{SSC} \text { ) }\end{array}$ & \\
\hline Macrophages & $\begin{array}{l}\text { CD11 bc }{ }^{+} \text {(gated in all cells except } \\
\text { granulocytes in FSC, SSC) }\end{array}$ & \\
\hline Granulocytes & $\begin{array}{l}\mathrm{CD} 11 \mathrm{bc}^{+} \text {granulocytes } \\
\text { granulocytes in } \mathrm{FSC}, \mathrm{SSC} \text { ) }\end{array}$ & \\
\hline \multirow[t]{2}{*}{ NK cells } & $\mathrm{CD}^{-} \mathrm{CD}^{-161 \mathrm{high}^{+}}$ & \\
\hline & Phenotype thymocytes & \\
\hline DN & $\mathrm{CD}_{4}^{-} \mathrm{CD}^{-}$ & (gated \\
\hline DP & $\mathrm{CD}^{+}{ }^{+} \mathrm{CD} 8^{+}$ & lymphocytes \\
\hline CD4 SP & $\mathrm{CD} 4^{+} \mathrm{CD}^{-}$ & in FSC, SSC) \\
\hline CD8 SP & $\mathrm{CD} 4^{-} \mathrm{CD} 8^{+}$ & \\
\hline
\end{tabular}

Table 2 | Identification of cell death.

\begin{tabular}{ll}
\hline & Phenotype \\
\hline Alive & Annexin $\mathrm{V}^{-} 7 A A D^{-}$ \\
Apoptosis & Annexin $\mathrm{V}^{+} 7 A \mathrm{AD}^{-}$ \\
Necrosis & Annexin $\mathrm{V}^{ \pm} 7 A \mathrm{AD}^{+}$ \\
\hline
\end{tabular}

$F_{2,41}=7.92, p=0.001$ and $\left.\eta^{2}=0.28\right)$ when compared to the Cont group $(p=0.009)$. Accordingly, $\mathrm{MS}_{2-15}$ displayed a significant increase in the immobility time (Figure 1B; $F_{2,41}=4.41$, $p=0.02$ and $\eta^{2}=0.18$ ) when compared with Cont animals $(p=0.049)$ and with $\mathrm{MS}_{7-20}$ group, in the FST $(p=0.03)$. No significant differences were observed between $\mathrm{MS}_{7-20}$ and Cont group (Figure 1B; $p=0.997$ ). Considering that FST is a highly demanding motor task, we performed the OF test to control for locomotor impairment that could underlie the significant reduction of activity observed in the FST. No differences were observed between groups in the total distance traveled in the arena (Figure 2A; $F_{2,42}=0.66, p=0.52$ ) and in the number (Figure 2B; $F_{2,42}=1.25, p=0.30$ ) and duration (Figure $2 \mathrm{C} ; F_{2,42}=1.4$, $p=0.30$ ) of rearings. In fact, MS, irrespectively from when it occurred, did not affect spontaneous locomotion (Figure 2A) or exploratory behavior (Figures 2B,C). Conversely, OF results also demonstrated that the percentage of time spent in the center of the arena was significantly reduced in the $\mathrm{MS}_{2-15}$ (Figure 2D; $F_{2,42}=3.41, p=0.04$, and $\left.\eta^{2}=0.14\right)$, when compared to Cont animals $(p=0.04)$, which is a sign of anxious-like behavior. $\mathrm{MS}_{7-20}$ did not differ from both Cont $(p=0.41)$ and $\mathrm{MS}_{2-15}$ $(p=0.52)$ groups in the percentage of time spent in the center of the arena. 


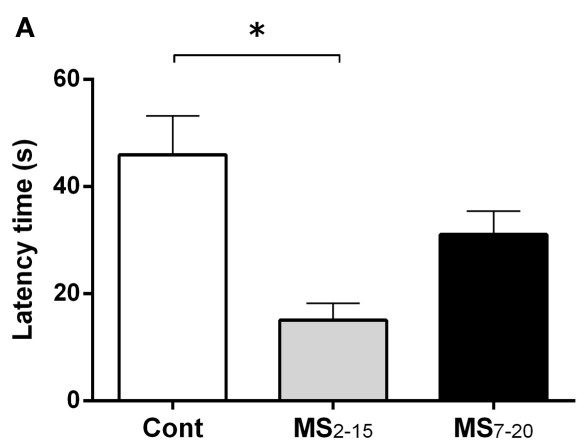

FIGURE 1 | Early maternal separation $\left(\mathrm{MS}_{2-15}\right)$ induced depressive-like behavior. (A) Latency to first immobility and (B) duration of immobility in the FST were assessed in Cont, $\mathrm{MS}_{2-15}$,
B

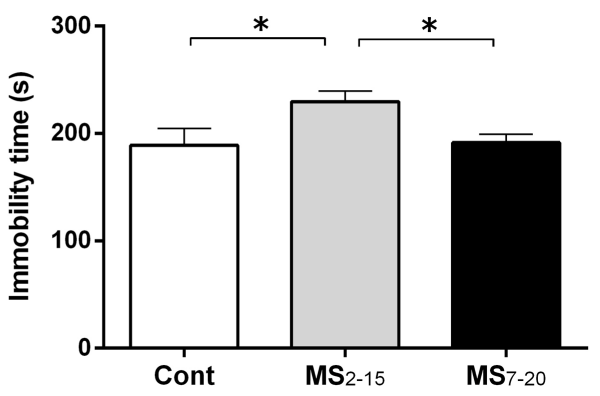

and $\mathrm{MS}_{7-20}$ groups at 3 months of age. Each bar represents the mean + SEM from 11 to 20 rats per group from one of two independent experiments.
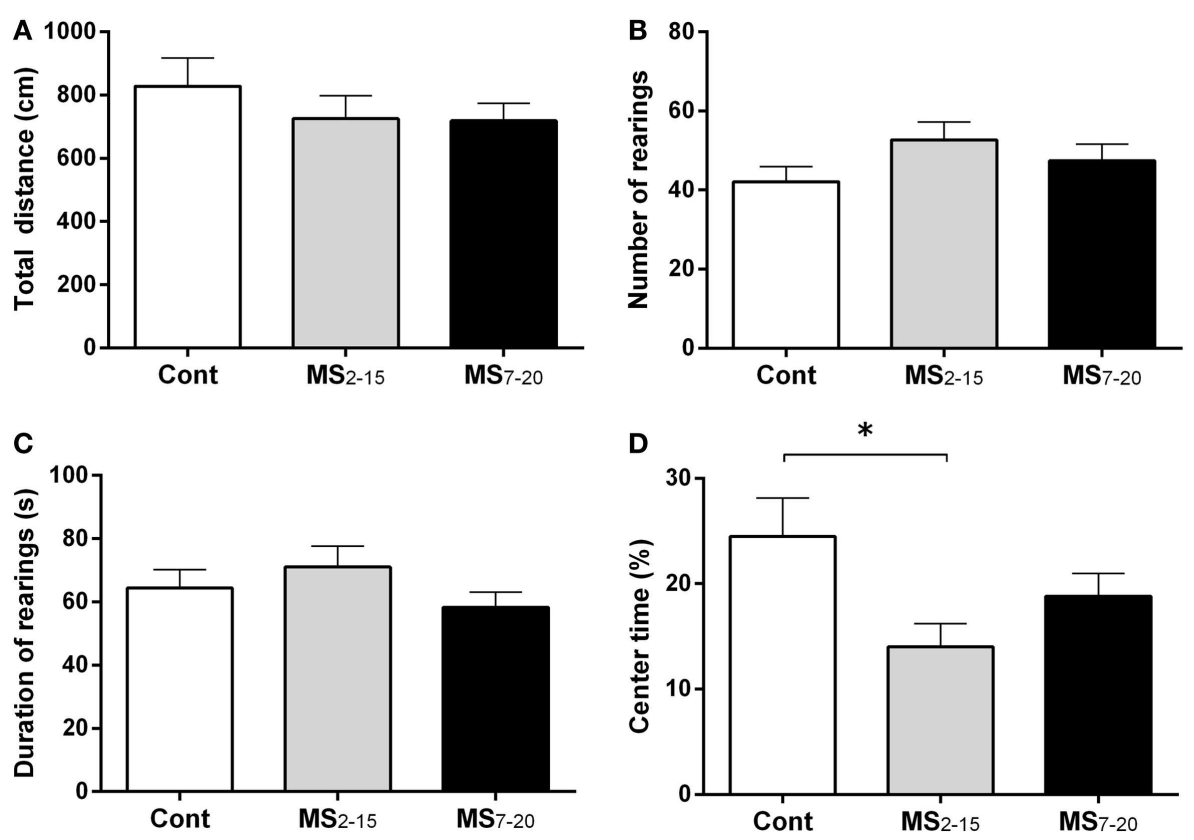

FIGURE 2 | $\mathrm{MS}_{2-15}$ group presented anxious-like behavior in the OF test The OF test was performed to assess (A) total distance, (B) number, (C) duration of rearings, and (D) time spent in the center of the OF arena in

Cont, $\mathrm{MS}_{2-15}$, and $\mathrm{MS}_{7-20}$ groups at 3 months of age. Each bar represents the mean + SEM from 11 to 20 rats per group from one of two independent experiments.

BOTH PERIODS OF MS CAUSED INCREASED CORTICOSTERONE LEVELS BUT ONLY EARLY MS TRIGGERED THYMIC AND SPLENIC CELL

\section{ALTERATIONS}

Corticosterone assessment revealed a long-lasting increase in basal corticosterone levels in both MS groups when compared with Cont animals (Figure 3; $F_{2,52}=6.58, p=0.003$, and $\eta^{2}=0.20$; Cont vs. $\mathrm{MS}_{2-15} p=0.003$ and Cont vs. $\left.\mathrm{MS}_{7-20} p=0.04\right)$.

Given the high sensitivity of the immune system to alterations in corticosteroid millieu, we analyzed the impact of MS on the weight of two of the most relevant immune system organs, the thymus, the primary lymphoid organ that supports $\mathrm{T}$ cell differentiation, and the spleen, a central organ of the peripheral immune system. No alterations were observed in the absolute (Figure 4B; $F_{2,69}=0.58, p=0.56$ ) and relative weight of the spleen (normalized to the body weight; Figure $4 \mathrm{C} ; F_{2,66}=0.05$ and $p=0.95$ ) between the three groups. However, MS animals showed a significant reduction in the thymus weight when compared with Cont (Figure 4D; $F_{2,64}=8.75, p=0.0004$, and $\eta^{2}=0.22$; Cont vs. $\mathrm{MS}_{2-15} p=0.001$ and Cont vs. $\left.\mathrm{MS}_{7-20} p=0.003\right)$; these differences were independent of the absolute animal body weight, since the same alterations were present when the thymus weight was normalized to the body weight (Figure 4E; $F_{2,62}=12.62$, $p<0.0001$, and $\eta^{2}=0.28$; Cont vs. $\mathrm{MS}_{2-15} p=0.0001$ and Cont vs. $\left.\mathrm{MS}_{7-20} p=0.0003\right)$. Moreover, no differences were seen on 


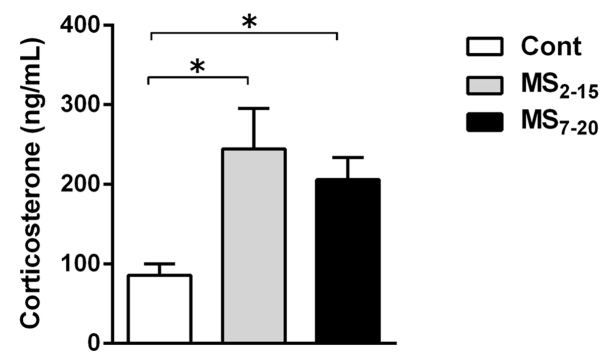

FIGURE 3 | Maternal separation induced increased corticosterone serum levels. Each bar represents the mean + SEM from 16 to 21 rats per group from two independent experiments.

the body weight of those animals (Figure $4 \mathbf{A} ; F_{2,67}=2.80$ and $p=0.07)$. Taking into account the decreased thymic weight, we next analyzed whether this was reflected in the proportion of the four main thymic cell populations: double negative (DN: $\mathrm{CD} 4{ }^{-} \mathrm{CD} 8^{-}$), double positive (DP: $\mathrm{CD} 4^{+} \mathrm{CD} 8^{+}$), CD4 single positive (CD4SP: $\mathrm{CD} 4{ }^{+} \mathrm{CD} 8^{-}$), and $\mathrm{CD} 8$ single positive (CD8SP: $\left.\mathrm{CD}^{-} \mathrm{CD}^{+}\right)$. No differences on thymic cell populations were present (Figure 5A; DN: $F_{2,63}=0.30, p=0.74$; DP: $F_{2,63}=1.25$, $p=0.29$; CD4SP: $F_{2,63}=0.06, p=0.94$; CD8SP: $F_{2,63}=0.01$, $p=0.99)$. We further studied the resistance of those populations to in vitro exposure to dexamethasone. Thymocytes from the $\mathrm{MS}_{2-15}$ group presented a decreased necrosis rate when compared to Cont and $\mathrm{MS}_{7-20}$ (Figure 5B; $F_{2,34}=9.75, p=0.0005$, and $\eta^{2}=0.34$; Cont vs. $\mathrm{MS}_{2-15} p=0.002$ and $\mathrm{MS}_{2-15}$ vs. $\mathrm{MS}_{7-20}$ $p=0.01$ ) and these alterations seemed to be mainly caused by the decreased necrosis observed among DP cells (Figure 5B; $F_{2,35}=8.82, p=0.0008$, and $\eta^{2}=0.34$; Cont vs. $\mathrm{MS}_{2-15} p=0.004$ and $\mathrm{MS}_{2-15}$ vs. $\mathrm{MS}_{7-20} p=0.002$ ). Moreover, thymus from $\mathrm{MS}_{2-15}$ animals also presented a lower proportion of alive DP cells when compared with Cont (Figure 5B; $F_{2,34}=5.11, p=0.011$, and $\eta^{2}=0.23$; Cont vs. $\left.\mathrm{MS}_{2-15} p=0.011\right)$. Regarding the peripheral immune system, a decreased percentage of $\mathrm{CD} 8^{+} \mathrm{T}$ cell was observed in the spleen of $\mathrm{MS}_{2-15}$ group when compared with both Cont and $\mathrm{MS}_{7-20}$ (Figure 6A; $F_{2,68}=8.54, p=0.0005$, and $\left.\eta^{2}=0.20\right)$. This led to an increased T cell CD4/CD8 ratio in the $\mathrm{MS}_{2-15}$ group (Figure $6 \mathrm{~B} ; F_{2,64}=6.87, p=0.002$, and $\eta^{2}=0.18$ ), while no alterations were seen in the T/B cells ratio. No differences were observed in the other spleen cell populations analyzed (Figures 6A,C; CD $4^{+} \mathrm{T}$ cells, B cells, granulocytes, macrophages, and NK cells).

\section{SERA CORTICOSTERONE LEVELS AND T CELL CD4/CD8 RATIO PREDICT DEPRESSIVE-LIKE BEHAVIOR}

The use of a linear regression model to predict depressive-like behavior revealed that corticosterone, per se, was a marginal statistical significant predictor of immobility in the FST $\left(F_{1,29}=4.02\right.$, $p=0.054)$. Instead, when both variables: corticosterone levels and the $\mathrm{T}$ cell $\mathrm{CD} 4 / \mathrm{CD} 8$ ratio were included, a significant model emerged $\left(F_{2,28}=9.71, p=0.001\right)$, explaining $37 \%$ of the variance. Increased corticosterone levels and higher T cell CD4/CD8 ratio were significant predictors of increased immobility in the FST (Table 3).

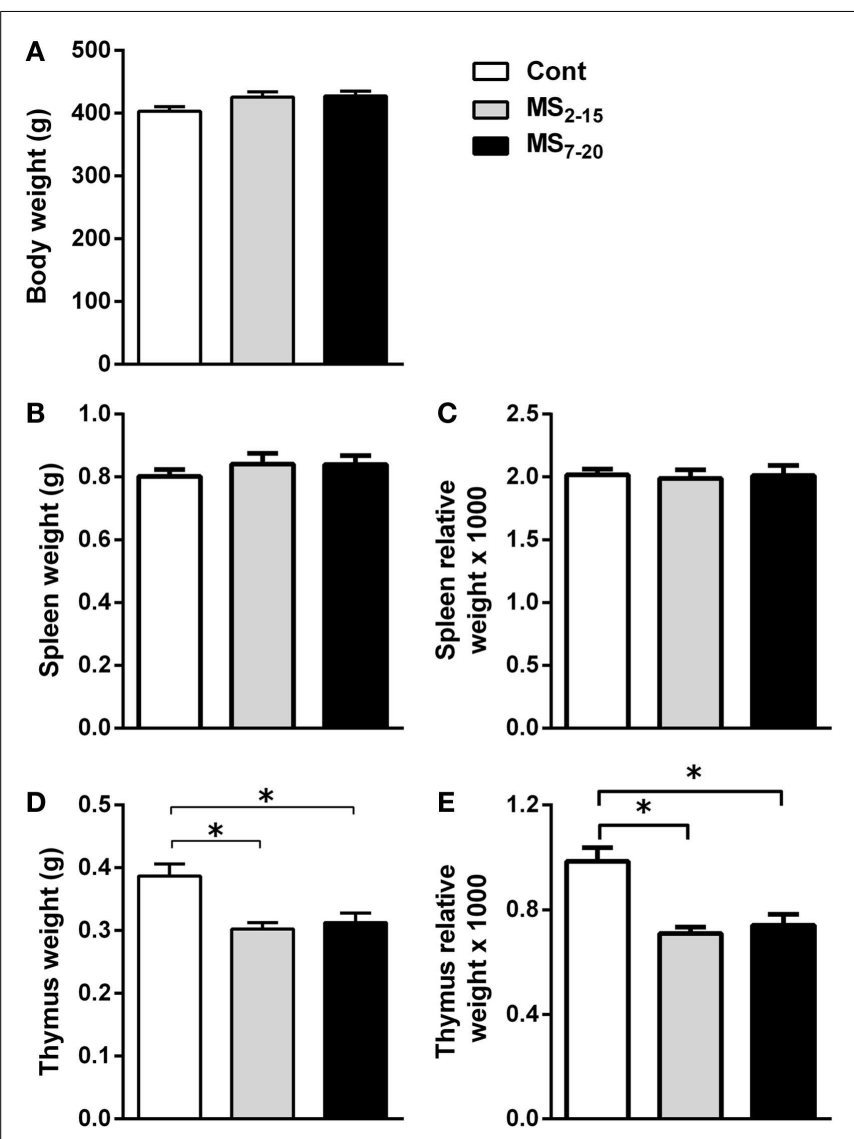

FIGURE 4 | Maternal separation caused a decrease in the thymus weight. (A) Body weight, (B) spleen weight, (C) spleen relative weight, (D) thymus weight, and (E) thymus relative weight were measured in Cont, $\mathrm{MS}_{2-15}$, and $\mathrm{MS}_{7-20}$ groups at 3 months of age. Each bar represents the mean + SEM from 18 to 27 rats per group from two independent experiments.

\section{DISCUSSION}

This study addressed the long-term effects of two time windows of MS on the HPA axis, immunological function, and depressive/anxious-like behaviors. We observed that, irrespectively of the time window, MS caused increased corticosterone sera levels in adulthood. However, only animals submitted to MS between the $2^{\text {nd }}$ and the $15^{\text {th }}$ postnatal days displayed immunological and behavioral alterations. Additionally, corticosterone sera levels and the $\mathrm{T}$ cell $\mathrm{CD} 4 / \mathrm{CD} 8$ ratio were shown to predict depressive-like behavior in this animal model.

The comparison between two time periods of MS sheds light on the critical periods of development in which early life stress strongly impacts on mood behavior, immune, and endocrine systems. The earlier separation period $\left(\mathrm{MS}_{2-15}\right)$ mimics the temporal window most widely used in the literature and overlaps most of the stress hypo-responsive period (Schmidt et al., 2011), while the $\mathrm{MS}_{7-20}$, with the same exposure duration and some overlap, occurs when some components of the HPA axis regulation are known to be already mature (Schmidt et al., 2011). Remarkably, both MS exposure periods impacted similarly on the adult HPA 


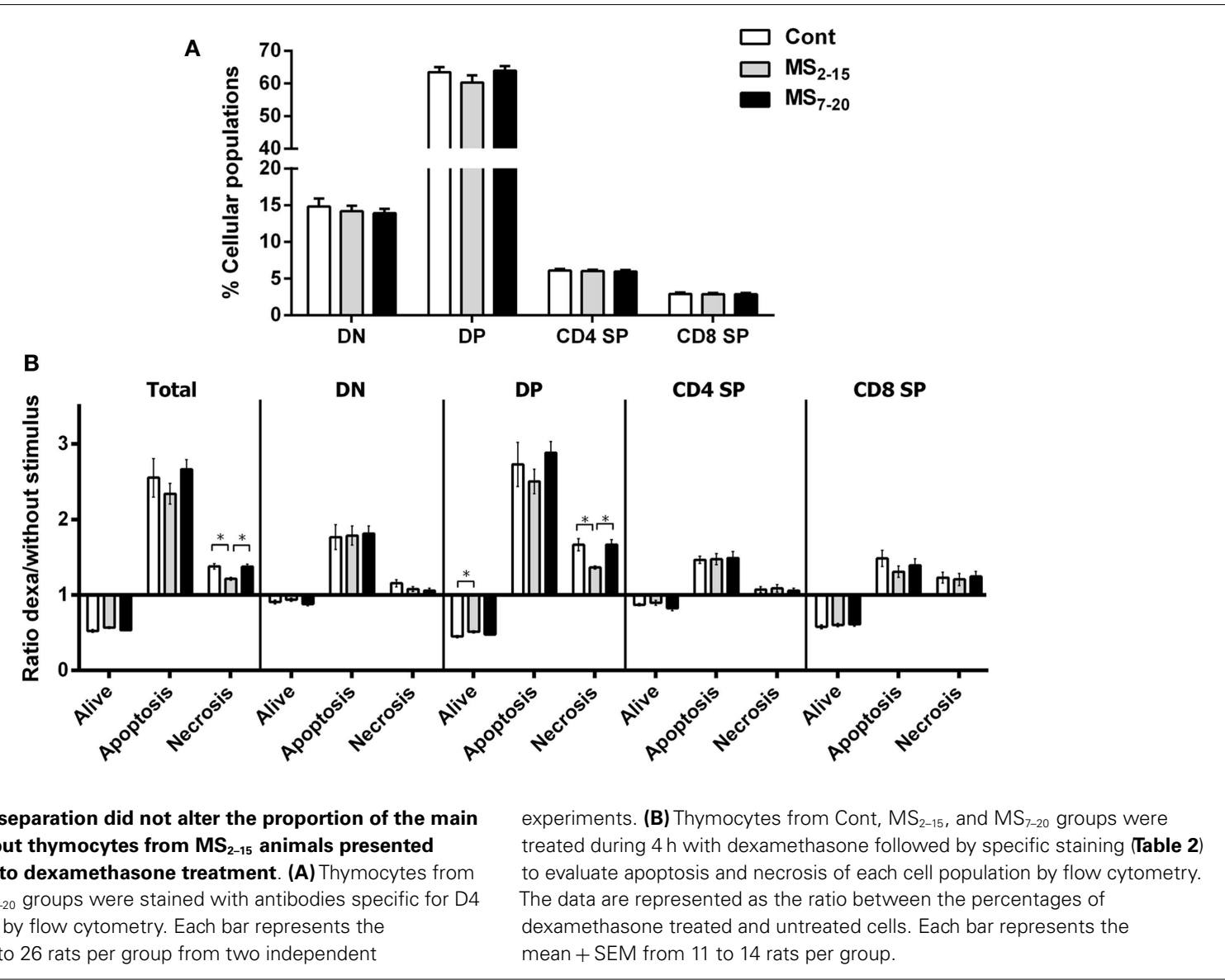

FIGURE 5 | Maternal separation did not alter the proportion of the main thymic populations but thymocytes from $\mathrm{MS}_{2-15}$ animals presented increased resistance to dexamethasone treatment. (A) Thymocytes from Cont, $\mathrm{MS}_{2-15}$, and $\mathrm{MS}_{7-20}$ groups were stained with antibodies specific for D4 and CD8 and analyzed by flow cytometry. Each bar represents the mean + SEM from 19 to 26 rats per group from two independent experiments. (B) Thymocytes from Cont, $\mathrm{MS}_{2-15}$, and $\mathrm{MS}_{7-20}$ groups were reated during $4 \mathrm{~h}$ with dexamethasone followed by specific staining (Table 2) mean + SEM from 11 to 14 rats per group.

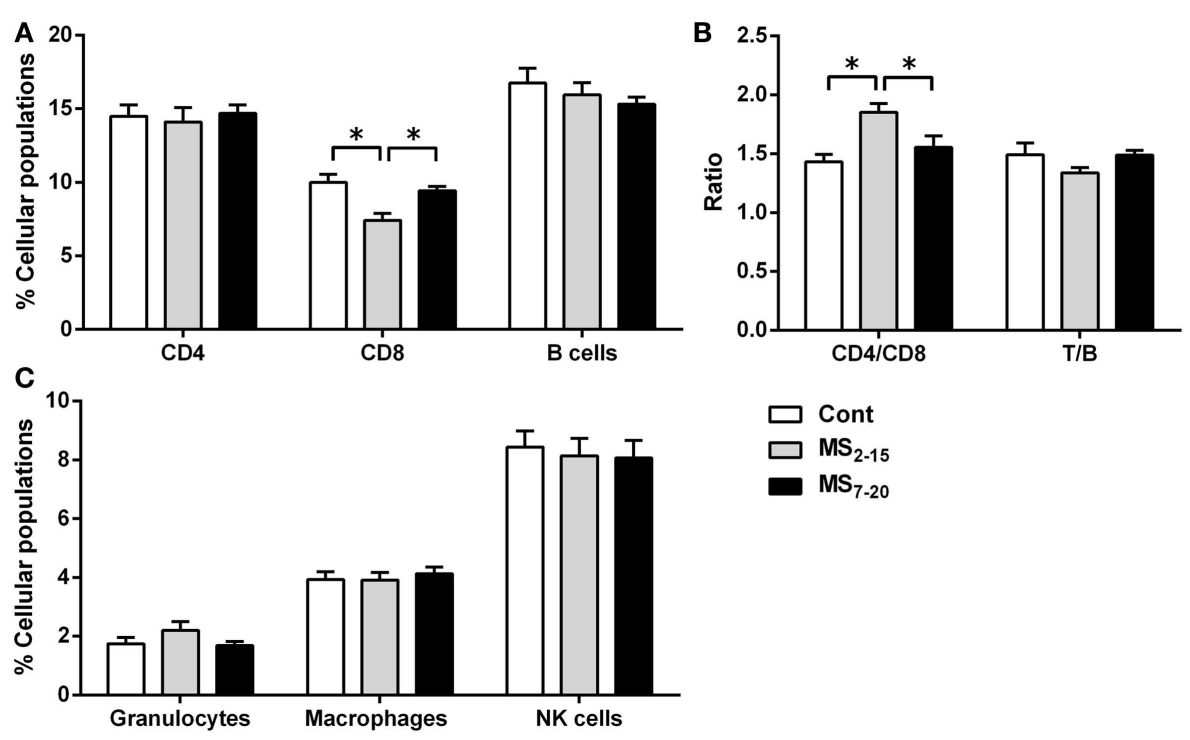

FIGURE 6 | Maternal separation between days 2 and 15 caused a decrease in the percentage of $\mathrm{CD8}^{+} \mathrm{T}$ cells and an increase in the $T$ cell CD4/CD8 ratio in the spleen of adult animals.

Splenocytes from Cont, $\mathrm{MS}_{2-15}$, and $\mathrm{MS}_{7-20}$ groups were labeled with specific antibodies (according to Table 1), and analyzed by flow cytometry, to identify the main spleen cell populations of the (A) adaptive immune system; (B) the ratios CD4/CD8T and T/B cells; and (C) the innate cells of the immune system. Each bar represents the mean + SEM from 24 to 27 rats per group from two independent experiments. 
Table 3 | Regression analysis predicting depressive-like behavior.

\begin{tabular}{llllll}
\hline & Variables & $\boldsymbol{R}^{\mathbf{2}}\left(\boldsymbol{R}^{\mathbf{2}}\right.$ adj $)$ & $\boldsymbol{F}(\mathbf{d f})$ & $\boldsymbol{\beta}$ & $\boldsymbol{t}$ \\
\hline Step 1 & Corticosterone level & $0.12(0.09)$ & $4.02(1,29)^{\#}$ & 0.35 & $2.0^{\#}$ \\
Step 2 & Corticosterone level & $0.41(0.37)$ & $9.71(2,28)^{*}$ & 0.44 & $3.0^{* *}$ \\
& T cell CD4/CD8 ratio & & 0.54 & $3.7^{* *}$ &
\end{tabular}

${ }^{*} p=0.05 ;{ }^{*} p<0.05 ;{ }^{*} p<0.01$.

axis basal function leading to increased basal corticosterone levels, suggesting that the postnatal week common to both MS periods (from postnatal day 7 to 15 , last days of the stress hypo-responsive period) is determinant in the programing effects on the HPA axis. Since this time window is critical for the maturation of the HPA axis, it is not surprising that the stress triggered by MS performed during this period, caused a long-lasting disruption in the HPA axis function leading to increased basal levels of corticosterone in the adult progeny. Similar results were observed by several other authors, even using slightly distinct MS protocols (Clarke, 1993; Slotten et al., 2006; Batalha et al., 2013). Conversely, decreased (Slotten et al., 2006) or even no alteration (Plotsky et al., 2005) in corticosterone basal levels in animals submitted to MS were also reported. Overall, most literature seems to corroborate that MS is a developmental disruptor of the neuroendocrine function with long-lasting effects on the HPA axis activity and responsiveness. However, even MS animals that do not present alterations in the basal levels of corticosterone show a hypersecretion of this molecule in response to a psychological stressor (Plotsky et al., 2005).

Of notice, anxious and depressive-like behaviors in adulthood were found only when MS was applied earlier, which indicates the existence of sensitive periods for stress-related behavioral programing. It would be interesting to next evaluate other dimensions of depressive-like behavior. Even though the behavioral test used in this study (FST) is the one most widely used to assess behavior despair in rodents (Petit-Demouliere et al., 2005; Sousa et al., 2006), it also displays strong correlations with other dimensions of depression such as hedonic behavior (Bessa et al., 2009b). The impact on mood observed in the $\mathrm{MS}_{2-15}$ group is in accordance with previous studies performed in the same developmental window (Kalinichev et al., 2002; Ruedi-Bettschen et al., 2005; Lee et al., 2007; Lambas-Senas et al., 2009; Holsboer and Ising, 2010) while, to our knowledge, no other studies evaluated mood in animals submitted to $\mathrm{MS}_{7-20}$.

The observed stress consequences on adult corticosterone levels and behavior observed in the $\mathrm{MS}_{2-15}$ group are unlikely a consequence of altered maternal behavior, since in a previous study we observed no maternal behavior differences or altered corticosteroid levels in the dams, 2 weeks after delivery (Mesquita et al., 2007). However, the maternal behavior of the $\mathrm{MS}_{7-20}$ group was not assessed and, indeed, some reports stated an increased active maternal care in animals submitted to MS that seems to buffer potential consequences of long separation periods (Zhang et al., 2004; Macri et al., 2008). This could be a potential mechanism by which $\mathrm{MS}_{7-20}$ are different from $\mathrm{MS}_{2-15}$; further investigation will help to clarify this issue.
Interestingly, the differential behavioral alterations observed in MS groups show that factors other than the HPA axis are necessary for the induction of anxious and depressive-like behaviors. We searched for parameters of the immune system. Of notice, we observed thymic atrophy in both MS treated groups, which may likely result from the well-described effect of the glucocorticoids (similarly increased in both MS groups) on the thymus (Ashwell et al., 2000a). To our knowledge, this is the first study that describes a decreased adult thymic weight in animals submitted to MS, associated with higher levels of corticosterone. Chen et al. (2012) have also analyzed male rats submitted to $4 \mathrm{~h}$ MS during the $2^{\text {nd }}$ and the $13^{\text {th }}$ postnatal day and failed to observe alterations in the thymic weight, as well as any alterations in basal levels of corticosterone. Curiously decreased thymic weight and increased serum levels of corticosterone are common alterations in both MS groups. Since the two MS periods used in this study overlap for 1 week, this suggests that the postnatal day 7-15 seems crucial for the programing effect in the corticosterone levels and that it may lead to the alterations in the thymus weight and in number of cells observed. Of interest, despite the decrease in thymus size, no alteration in the proportion of the four main thymocyte populations was observed. These results are in accordance with those from Kruschinski et al. (2008) in which MS was performed from postnatal day 1 to 28 . However, in the present report, after in vitro dexamethasone treatment (known to induce thymocyte death) only the $\mathrm{MS}_{2-15}$ group presented increased resistance to cell death; mainly due to the increased resistance in the DP cells, the thymocyte population know to be more susceptible to glucocorticoids-induced cell death (Ashwell et al., 2000b). The differential response of the MS groups indicates that additional programing alterations exist in the thymocytes causing glucocorticoid resistance when MS is imposed earlier $\left(\mathrm{MS}_{2-15}\right)$. One of the mechanisms that may underlie the alterations in the thymocytes resistance in the $\mathrm{MS}_{2-15}$ group is an impaired glucocorticoid receptor (GR) function of the thymocytes. Such dysfunction in GR has also been associated with alterations in the cytokine milieu (Silverman and Sternberg, 2012). We did not analyze the cytokine profile of these animals, but alterations in the cytokine milieu of animals submitted to MS during the first 2 weeks of life have been shown by others (Dimatelis et al., 2012; Avitsur et al., 2013), which can be indicative of a simultaneous mechanism that contributes to the thymocyte glucocorticoid resistance observed in the $\mathrm{MS}_{2-15}$ group.

The effect of MS on the peripheral immune system also seems to be time specific. Only the earlier period of MS caused a decrease in the percentage of $\mathrm{CD} 8^{+} \mathrm{T}$ cells in the spleen and, consequently, an increase in the T cell CD4/CD8 ratio. Further supporting that timing of MS is crucial when MS is imposed to rats between postnatal days 1 and 28, Kruschinski et al. (2008) did not observe alterations in spleen immune cell populations. The $\mathrm{T}$ cell alterations observed in the spleen of $\mathrm{MS}_{2-15}$ animals do not seem to be a consequence of impairment in thymic $\mathrm{T}$ cell differentiation, since no differences in the four main population of the thymus were observed; but rather an alteration in the peripheral homeostatic mechanisms (Rocha et al., 1989). The decreased percentage of $\mathrm{CD} 8^{+} \mathrm{T}$ cells in the spleen can be caused by a deficient signaling to support cell survival or to an increased cell death in these cells, which deserve further investigation. Interestingly, a recent study 
showed that $\mathrm{CD} 8^{+} \mathrm{T}$ cells display a more pronounced expression of dopaminergic transporters and receptors when compared with $\mathrm{CD}^{+} \mathrm{T}$ cells (Mignini et al., 2013) and, dopamine was shown to inhibit the proliferation of $\mathrm{T}$ cells, particularly of $\mathrm{CD} 8^{+} \mathrm{T}$ cells (Saha et al., 2001). Given that MS impacts on the dopaminergic system, it is plausible that this might constitute an additional mechanism for the present finding of reduced $\mathrm{CD} 8^{+} \mathrm{T}$ cells ( $\mathrm{Li}$ et al., 2013). Moreover, these $\mathrm{T}$ cells are primarily involved in immune response to pathogens (mainly virus) and tumor cells, and are also implicated in transplant rejection. Curiously, C56BL/6 mice exposed to MS between postnatal days 1 and 14 were shown to present increased susceptibility to influenza virus infection; however, the levels of $\mathrm{CD} 8^{+} \mathrm{T}$ cells were not evaluated in these study (Avitsur et al., 2006).

Our findings are novel in revealing an increased T cell CD4/CD8 ratio, which is a highly preserved ratio within strains of animals (Rocha et al., 1989; Sim et al., 1998). Of notice, another rodent model of depressive-like behavior, induced by prenatal administration of dexamethasone, showed that adult males similarly display increased $\mathrm{T}$ cell $\mathrm{CD} 4 / \mathrm{CD} 8$ ratio and that the percentage of $\mathrm{CD}^{+} \mathrm{T}$ cells is negatively correlated with the latency in the FST (Roque et al., 2011). In humans and monkeys submitted to early life stress, alterations in $\mathrm{T}$ cell $\mathrm{CD} 4 / \mathrm{CD} 8$ ratio have also been reported (Lewis et al., 2000; Gogberashvili, 2006), even though in the opposite direction of what we describe herein. Remarkably, our results reveal that differences in immune cell populations are only present in animals displaying behavioral alterations, suggesting that the programing effects caused by MS impact not only in the endocrine system but also in the immune and central nervous systems, highlighting the interplay between them. Curiously, lower proportion of $\mathrm{CD}^{+} \mathrm{T}$ cells and a higher $\mathrm{T}$ cell CD4/CD8 ratio have been associated with lower levels of hippocampal neuronal proliferation (Huang et al., 2010). Moreover, although disputable, most studies show that MS decreases hippocampal cell proliferation (Hulshof et al., 2011), which in itself is associated with depressive-like behavior (Bessa et al., 2009a; Song and Wang, 2011).

The fact that the two MS periods do not overlap in the first and third postnatal week could also be crucial for the distinct effects, we observed in behavior and in parameters of the immune system. Considering that during the first postnatal week significant differences in the number and maturation process of GR in the hypothalamus, pituitary, and hippocampus were observed (De Kloet et al., 1988), one can speculate that stressful events during this very immature period could be fairly impactful on long-term behavior. In fact, early life events may lead to long-term epigenetic effects such as down regulation of hippocampal GR through the increased methylation patter in the coding gene (Weaver et al., 2004). A similar mechanism could also be caused by very early MS, since the first postnatal week is the most immature period of the HPA axis control. In the $\mathrm{MS}_{7-20}$ period, the HPA axis already presents an increased degree of maturation and number of GR in critical regions for HPA axis control (Vazquez and Akil, 1993). Of interest, GR are solely found in the hippocampus in the second postnatal week (Vazquez and Akil, 1993). The presence of GR (even in low levels) during the second and third postnatal week could be crucial for the organism to respond to stressful situations and buffer some of the long-term behavioral effects, such as anxious and depressive behaviors. Although speculative, this could be a likely explanation since we observed an increased anxious and depressive-like phenotype in the earlier MS group $\left(\mathrm{MS}_{2-15}\right)$ and not in the later one $\left(\mathrm{MS}_{7-20}\right)$.

As an attempt to assess the role of both corticosterone levels and $\mathrm{T}$ cell $\mathrm{CD} 4 / \mathrm{CD} 8$ ratio in the depressive-like behavior observed in our MS model, we performed a regression analysis. Both predictors explained $37 \%$ of the immobility time in the FST, suggesting a synergetic contribution of endocrine and immunological factors in the prediction of the depressive-like behavior observed in the MS animals. Of notice, corticosterone per se, accounted only for $9 \%$ of the variance and was merely a marginal significant predictor. We failed to find any predictors of anxious-like behavior. One should take into account that the depressive-like behavior, the increased corticosterone levels, and the alterations in the immune system seem to be related and caused by the effect of MS in an early life period. Even though additional studies are needed, our data suggests that this information might be potentially used to determine whether the predictive model for the depressive-like behavior can be a tool to predict if children submitted to adverse experiences in early life are more prone to develop mood disorders, which could eventually help in anticipating diagnosis of depression.

Altogether, this study shows that the timing in which early life stress is applied determines its long-lasting effects in several body systems, and that these interact in ways that may be predictive of mood behavior alterations in the adulthood.

\section{AUTHOR CONTRIBUTIONS}

S. Roque performed the immune cells phenotyping experiments and analysis. A. R. Mesquita performed the MS protocol, the behavior assessment and analysis, and the corticosterone measurement. Both S. Roque and A. R. Mesquita performed the statistical data analysis. All authors contributed to the planning of the experiments, data interpretation, writing of the manuscript, and approved the final version of the manuscript.

\section{ACKNOWLEDGMENTS}

We acknowledge the Portuguese Foundation for Science and Technology (FCT) for providing a fellowship to $S$. Roque (SFRH/BPD/72710/2010). This work was also supported by FCT grants (co-financed by COMPETE funds) PTDC/SAUNEU/105180/2008 and PTDC/PSI-PCO/116612/2010 and cofinanced by the Portuguese North Regional Operational Program (ON.2 - O Novo Norte) under the National Strategic Reference Framework (QREN), through the European Regional Development Fund (FEDER).

\section{REFERENCES}

Aisa, B., Tordera, R., Lasheras, B., Del Rio, J., and Ramirez, M. J. (2007). Cognitive impairment associated to HPA axis hyperactivity after maternal separation in rats. Psychoneuroendocrinology 32, 256-266. doi:10.1016/j.psyneuen.2006.12. 013

Ashwell, J. D., Lu, F. W., and Vacchio, M. S. (2000a). Glucocorticoids in T cell development and function. Annu. Rev. Immunol. 18, 309-345. doi:10.1146/annurev. immunol.18.1.309 
Ashwell, J. D., Lu, F. W., and Vacchio, M. S. (2000b). Glucocorticoids in T cell development and function*. Annu. Rev. Immunol. 18, 309-345. doi:10.1146/annurev. immunol.18.1.309

Avitsur, R., Hunzeker, J., and Sheridan, J. F. (2006). Role of early stress in the individual differences in host response to viral infection. Brain Behav. Immun. 20, 339-348. doi:10.1016/j.bbi.2005.09.006

Avitsur, R., Maayan, R., and Weizman, A. (2013). Neonatal stress modulates sickness behavior: role for proinflammatory cytokines. J. Neuroimmunol. 257, 59-66. doi:10.1016/j.jneuroim.2013.02.009

Batalha, V. L., Pego, J. M., Fontinha, B. M., Costenla, A. R., Valadas, J. S., Baqi, Y., et al. (2013). Adenosine A(2A) receptor blockade reverts hippocampal stressinduced deficits and restores corticosterone circadian oscillation. Mol. Psychiatry 18, 320-331. doi:10.1038/mp.2012.8

Bessa, J. M., Ferreira, D., Melo, I., Marques, F., Cerqueira, J. J., Palha, J. A., et al. (2009a). The mood-improving actions of antidepressants do not depend on neurogenesis but are associated with neuronal remodeling. Mol. Psychiatry 14, 739. doi:10.1038/mp.2008.119

Bessa, J. M., Mesquita, A. R., Oliveira, M., Pego, J. M., Cerqueira, J. J., Palha, J. A., et al. (2009b). A trans-dimensional approach to the behavioral aspects of depression. Front. Behav. Neurosci. 3:1. doi:10.3389/neuro.08.001.2009

Cao, X., Huang, S., Cao, J., Chen, T., Zhu, P., Zhu, R., et al. (2013). The timing of maternal separation affects morris water maze performance and long-term potentiation in male rats. Dev. Psychobiol. doi:10.1002/dev.21130

Chen, J., Evans, A. N., Liu, Y., Honda, M., Saavedra, J. M., and Aguilera, G. (2012). Maternal deprivation in rats is associated with corticotrophin-releasing hormone $(\mathrm{CRH})$ promoter hypomethylation and enhances $\mathrm{CRH}$ transcriptional responses to stress in adulthood. J. Neuroendocrinol. 24, 1055-1064. doi:10.1111/j.1365-2826.2012.02306.x

Clarke, A. S. (1993). Social rearing effects on HPA axis activity over early development and in response to stress in rhesus monkeys. Dev. Psychobiol. 26, 433-446. doi:10.1002/dev.420260802

Cohen, J. (1988). Statistical Power Analysis for the Behavioral Sciences. New York, NY: Routledge Academic.

Cohen, S., Janicki-Deverts, D., and Miller, G. E. (2007). Psychological stress and disease. JAMA 298, 1685-1687. doi:10.1001/jama.298.14.1685

Colorado, R. A., Shumake, J., Conejo, N. M., Gonzalez-Pardo, H., and GonzalezLima, F. (2006). Effects of maternal separation, early handling, and standard facility rearing on orienting and impulsive behavior of adolescent rats. Behav. Processes 71, 51-58. doi:10.1016/j.beproc.2005.09.007

De Kloet, E. R., Rosenfeld, P., Van Eekelen, J. A., Sutanto, W., and Levine, S. (1988). Stress, glucocorticoids and development. Prog. Brain Res. 73, 101-120. doi:10.1016/S0079-6123(08)60500-2

Diehl, L. A., Alvares, L. O., Noschang, C., Engelke, D., Andreazza, A. C., Goncalves, C. A., et al. (2012). Long-lasting effects of maternal separation on an animal model of post-traumatic stress disorder: effects on memory and hippocampal oxidative stress. Neurochem. Res. 37, 700-707. doi:10.1007/s11064-011-0660-6

Dimatelis, J. J., Pillay, N. S., Mutyaba, A. K., Russell, V. A., Daniels, W. M., and Stein, D. J. (2012). Early maternal separation leads to down-regulation of cytokine gene expression. Metab. Brain Dis. 27, 393-397. doi:10.1007/s11011012-9304-z

Dinan, T. G. (2005). Stress: the shared common component in major mental illnesses. Eur. Psychiatry 20(Suppl. 3), S326-S328. doi:10.1016/S0924-9338(05) 80184- 1

Garner, B., Wood, S. J., Pantelis, C., and Van Den Buuse, M. (2007). Early maternal deprivation reduces prepulse inhibition and impairs spatial learning ability in adulthood: no further effect of post-pubertal chronic corticosterone treatment. Behav. Brain Res. 176, 323-332. doi:10.1016/j.bbr.2006.10.020

Gogberashvili, K. (2006). Maternal deprivation, acute respiratory infections and immune regulation. Indian J. Pediatr. 73, 995-997. doi:10.1007/BF02758305

Holsboer, F., and Ising, M. (2010). Stress hormone regulation: biological role and translation into therapy. Annu. Rev. Psychol. 61, C101-C111. doi:10.1146/ annurev.psych.093008.100321

Huang, G. J., Smith, A. L., Gray, D. H., Cosgrove, C., Singer, B. H., Edwards, A., et al. (2010). A genetic and functional relationship between T cells and cellular proliferation in the adult hippocampus. PLoS Biol. 8:e1000561. doi:10.1371/journal. pbio. 1000561

Hulshof, H. J., Novati, A., Sgoifo, A., Luiten, P. G., Den Boer, J. A., and Meerlo, P. (2011). Maternal separation decreases adult hippocampal cell proliferation and impairs cognitive performance but has little effect on stress sensitivity and anxiety in adult Wistar rats. Behav. Brain Res. 216, 552-560. doi:10.1016/j.bbr.2010. 08.038

Kalinichev, M., Easterling, K. W., Plotsky, P. M., and Holtzman, S. G. (2002). Longlasting changes in stress-induced corticosterone response and anxiety-like behaviors as a consequence of neonatal maternal separation in Long-Evans rats. Pharmacol. Biochem. Behav. 73, 131-140. doi:10.1016/S0091-3057(02)00781-5

Kruschinski, C., Skripuletz, T., Bedoui, S., Raber, K., Straub, R. H., Hoffmann, T., et al. (2008). Postnatal life events affect the severity of asthmatic airway inflammation in the adult rat. J. Immunol. 180, 3919-3925. doi:10.4049/jimmunol.180.6.3919

Lambas-Senas, L., Mnie-Filali, O., Certin, V., Faure, C., Lemoine, L., Zimmer, L., et al. (2009). Functional correlates for 5-HT(1A) receptors in maternally deprived rats displaying anxiety and depression-like behaviors. Prog. Neuropsychopharmacol. Biol. Psychiatry 33, 262-268. doi:10.1016/j.pnpbp.2008.11.017

Lee, J. H., Kim, H. J., Kim, J. G., Ryu, V., Kim, B. T., Kang, D. W., et al. (2007). Depressive behaviors and decreased expression of serotonin reuptake transporter in rats that experienced neonatal maternal separation. Neurosci. Res. 58, 32-39. doi:10.1016/j.neures.2007.01.008

Lehmann, J., Russig, H., Feldon, J., and Pryce, C. R. (2002). Effect of a single maternal separation at different pup ages on the corticosterone stress response in adult and aged rats. Pharmacol. Biochem. Behav. 73, 141-145. doi:10.1016/S0091-3057(02)00788-8

Lewis, M. H., Gluck, J. P., Petitto, J. M., Hensley, L. L., and Ozer, H. (2000). Early social deprivation in nonhuman primates: long-term effects on survival and cellmediated immunity. Biol. Psychiatry 47, 119-126. doi:10.1016/S0006-3223(99) 00238-3

Li, M., Xue, X., Shao, S., Shao, F., and Wang, W. (2013). Cognitive, emotional and neurochemical effects of repeated maternal separation in adolescent rats. Brain Res. 1518, 82-90. doi:10.1016/j.brainres.2013.04.026

Liu, D., Diorio, J., Tannenbaum, B., Caldji, C., Francis, D., Freedman, A., et al. (1997). Maternal care, hippocampal glucocorticoid receptors, and hypothalamicpituitary-adrenal responses to stress. Science 277, 1659-1662. doi:10.1126/ science.277.5332.1659

Macri, S., Chiarotti, F., and Wurbel, H. (2008). Maternal separation and maternal care act independently on the development of HPA responses in male rats. Behav. Brain Res. 191, 227-234. doi:10.1016/j.bbr.2008.03.031

Marais, L., Van Rensburg, S. J., Van Zyl, J. M., Stein, D. J., and Daniels, W. M. (2008). Maternal separation of rat pups increases the risk of developing depressive-like behavior after subsequent chronic stress by altering corticosterone and neurotrophin levels in the hippocampus. Neurosci. Res. 61, 106-112. doi:10.1016/j.neures.2008.01.011

Martisova, E., Solas, M., Horrillo, I., Ortega, J. E., Meana, J. J., Tordera, R. M., et al. (2012). Long lasting effects of early-life stress on glutamatergic/GABAergic circuitry in the rat hippocampus. Neuropharmacology 62, 1944-1953. doi:10.1016/ j.neuropharm.2011.12.019

Mathers, C. D., and Loncar, D. (2006). Projections of global mortality and burden of disease from 2002 to 2030. PLoS Med.3:e442. doi:10.1371/journal.pmed.0030442

Matthews, K., and Robbins, T. W. (2003). Early experience as a determinant of adult behavioural responses to reward: the effects of repeated maternal separation in the rat. Neurosci. Biobehav. Rev. 27, 45-55. doi:10.1016/S0149-7634(03)00008-3

Meaney, M. J., Aitken, D. H., Viau, V., Sharma, S., and Sarrieau, A. (1989). Neonatal handling alters adrenocortical negative feedback sensitivity and hippocampal type II glucocorticoid receptor binding in the rat. Neuroendocrinology 50, 597-604. doi:10.1159/000125287

Mesquita, A. R., Pego, J. M., Summavielle, T., Maciel, P., Almeida, O. F., and Sousa, N. (2007). Neurodevelopment milestone abnormalities in rats exposed to stress in early life. Neuroscience 147, 1022-1033. doi:10.1016/j.neuroscience.2007.04.007

Mesquita, A. R., Wegerich, Y., Patchev, A. V., Oliveira, M., Leao, P., Sousa, N., et al. (2009). Glucocorticoids and neuro- and behavioural development. Semin. Fetal Neonatal Med. 14, 130-135. doi:10.1016/j.siny.2008.11.002

Michaels, C. C., and Holtzman, S. G. (2007). Enhanced sensitivity to naltrexoneinduced drinking suppression of fluid intake and sucrose consumption in maternally separated rats. Pharmacol. Biochem. Behav. 86, 784-796. doi:10.1016/j.pbb. 2007.03.007

Mignini, F., Sabbatini, M., Capacchietti, M., Amantini, C., Bianchi, E., Artico, M., et al. (2013). T-cell subpopulations express a different pattern of dopaminergic markers in intra- and extra-thymic compartments. J. Biol. Regul. Homeost. Agents $27,463-475$. 
Miller, A. H. (2010). Depression and immunity: a role for T cells? Brain Behav. Immun. 24, 1-8. doi:10.1016/j.bbi.2009.09.009

Nemeroff, C. B. (2004). Neurobiological consequences of childhood trauma. J. Clin. Psychiatry 65(Suppl. 1), 18-28.

Petit-Demouliere, B., Chenu, F., and Bourin, M. (2005). Forced swimming test in mice: a review of antidepressant activity. Psychopharmacology (Berl.) 177, 245-255. doi:10.1007/s00213-004-2048-7

Plotsky, P. M., and Meaney, M. J. (1993). Early, postnatal experience alters hypothalamic corticotropin-releasing factor (CRF) mRNA, median eminence CRF content and stress-induced release in adult rats. Brain Res. Mol. Brain Res. 18, 195-200. doi:10.1016/0169-328X(93)90189-V

Plotsky, P. M., Thrivikraman, K. V., Nemeroff, C. B., Caldji, C., Sharma, S., and Meaney, M. J. (2005). Long-term consequences of neonatal rearing on central corticotropin-releasing factor systems in adult male rat offspring. Neuropsychopharmacology 30, 2192-2204. doi:10.1038/sj.npp.1300769

Rocha, B., Dautigny, N., and Pereira, P. (1989). Peripheral T lymphocytes: expansion potential and homeostatic regulation of pool sizes and CD4/CD8 ratios in vivo. Eur. J. Immunol. 19, 905-911. doi:10.1002/eji.1830190518

Roque, S., Oliveira, T. G., Nobrega, C., Barreira-Silva, P., Nunes-Alves, C., Sousa, N., et al. (2011). Interplay between depressive-like behavior and the immune system in an animal model of prenatal dexamethasone administration. Front. Behav. Neurosci. 5:4. doi:10.3389/fnbeh.2011.00004

Ruedi-Bettschen, D., Pedersen, E. M., Feldon, J., and Pryce, C. R. (2005). Early deprivation under specific conditions leads to reduced interest in reward in adulthood in Wistar rats. Behav. Brain Res. 156, 297-310. doi:10.1016/j.bbr.2004. 06.001

Saha, B., Mondal, A. C., Majumder, J., Basu, S., and Dasgupta, P. S. (2001). Physiological concentrations of dopamine inhibit the proliferation and cytotoxicity of human CD4+ and CD8+ T cells in vitro: a receptor-mediated mechanism. Neuroimmunomodulation 9, 23-33. doi:10.1159/000049004

Schmidt, M. V., Wang, X. D., and Meijer, O. C. (2011). Early life stress paradigms in rodents: potential animal models of depression? Psychopharmacology (Berl.) 214, 131-140. doi:10.1007/s00213-010-2096-0

Seckl, J. R. (2008). Glucocorticoids, developmental 'programming' and the risk of affective dysfunction. Prog. Brain Res. 167, 17-34. doi:10.1016/S0079-6123(07) 67002-2

Shalev, U., and Kafkafi, N. (2002). Repeated maternal separation does not alter sucrose-reinforced and open-field behaviors. Pharmacol. Biochem. Behav. 73, 115-122. doi:10.1016/S0091-3057(02)00756-6

Silverman, M. N., and Sternberg, E. M. (2012). Glucocorticoid regulation of inflammation and its functional correlates: from HPA axis to glucocorticoid receptor dysfunction. Ann. N. Y. Acad. Sci. 1261, 55-63. doi:10.1111/j.1749-6632.2012. 06633.x

Sim, B. C., Aftahi, N., Reilly, C., Bogen, B., Schwartz, R. H., Gascoigne, N. R., et al. (1998). Thymic skewing of the CD4/CD8 ratio maps with the T-cell receptor alpha-chain locus. Curr. Biol. 8, 701-704. doi:10.1016/S0960-9822(98)70276-3

Slotten, H. A., Kalinichev, M., Hagan, J. J., Marsden, C. A., and Fone, K. C. (2006). Long-lasting changes in behavioural and neuroendocrine indices in the rat following neonatal maternal separation: gender-dependent effects. Brain Res. 1097, 123-132. doi:10.1016/j.brainres.2006.04.066

Song, C., and Wang, H. (2011). Cytokines mediated inflammation and decreased neurogenesis in animal models of depression. Prog. Neuropsychopharmacol. Biol. Psychiatry 35, 760-768. doi:10.1016/j.pnpbp.2010.06.020

Sousa, N., Almeida, O. F., and Wotjak, C. T. (2006). A hitchhiker's guide to behavioral analysis in laboratory rodents. Genes Brain Behav. 5(Suppl. 2), 5-24. doi:10.1111/j.1601-183X.2006.00228.x

Vazquez, D. M., and Akil, H. (1993). Pituitary-adrenal response to ether vapor in the weanling animal: characterization of the inhibitory effect of glucocorticoids on adrenocorticotropin secretion. Pediatr. Res. 34, 646-653. doi:10.1203/00006450199311000-00017

Weaver, I. C., Cervoni, N., Champagne, F. A., D’Alessio, A. C., Sharma, S., Seckl, J. R., et al. (2004). Epigenetic programming by maternal behavior. Nat. Neurosci. 7, 847-854. doi:10.1038/nn1276

Zhang, T. Y., Parent, C., Weaver, I., and Meaney, M. J. (2004). Maternal programming of individual differences in defensive responses in the rat. Ann. N. Y. Acad. Sci. 1032, 85-103. doi:10.1196/annals.1314.007

Conflict of Interest Statement: The authors declare that the research was conducted in the absence of any commercial or financial relationships that could be construed as a potential conflict of interest.

Received: 08 December 2013; accepted: 08 May 2014; published online: 22 May 2014. Citation: Roque S, Mesquita AR, Palha JA, Sousa N and Correia-Neves M (2014) The behavioral and immunological impact of maternal separation: a matter of timing. Front. Behav. Neurosci. 8:192. doi: 10.3389/fnbeh.2014.00192

This article was submitted to the journal Frontiers in Behavioral Neuroscience. Copyright (c) 2014 Roque, Mesquita, Palha, Sousa and Correia-Neves. This is an openaccess article distributed under the terms of the Creative Commons Attribution License (CC BY). The use, distribution or reproduction in other forums is permitted, provided the original author(s) or licensor are credited and that the original publication in this journal is cited, in accordance with accepted academic practice. No use, distribution or reproduction is permitted which does not comply with these terms. 